\title{
JUNB suppresses distant metastasis by influencing the initial metastatic stage
}

\author{
Juliane Wutschka ${ }^{1,2}$ - Bettina Kast ${ }^{1}$ - Melanie Sator-Schmitt ${ }^{1}$. Sila Appak-Baskoy ${ }^{1,6,7}$. Jochen Hess ${ }^{3,4}$. \\ Hans-Peter Sinn ${ }^{5} \cdot$ Peter Angel $^{1}$ (1) $\cdot$ Marina Schorpp-Kistner ${ }^{1}$ (I)
}

Received: 19 November 2020 / Accepted: 23 June 2021 / Published online: 19 July 2021

(c) The Author(s) 2021

\begin{abstract}
The complex interactions between cells of the tumor microenvironment and cancer cells are considered a major determinant of cancer progression and metastasis. Yet, our understanding of the mechanisms of metastatic disease is not sufficient to successfully treat patients with advanced-stage cancer. JUNB is a member of the AP-1 transcription factor family shown to be frequently deregulated in human cancer and associated with invasion and metastasis. A strikingly high stromal JUNB expression in human breast cancer samples prompted us to functionally investigate the consequences of JUNB loss in cells of the tumor microenvironment on cancer progression and metastasis in mice. To adequately mimic the clinical situation, we applied a syngeneic spontaneous breast cancer metastasis model followed by primary tumor resection and identified stromal JUNB as a potent suppressor of distant metastasis. Comprehensive characterization of the JUNB-deficient tumor microenvironment revealed a strong influx of myeloid cells into primary breast tumors and lungs at early metastatic stage. In these infiltrating neutrophils, BV8 and MMP9, proteins promoting angiogenesis and tissue remodeling, were specifically upregulated in a JUNB-dependent manner. Taken together, we established stromal JUNB as a strong suppressor of distant metastasis. Consequently, therapeutic strategies targeting AP-1 should be carefully designed not to interfere with stromal JUNB expression as this may be detrimental for cancer patients.
\end{abstract}

Keywords Metastasis $\cdot$ Transcription factor $\cdot$ Tumor microenvironment

Marina Schorpp-Kistner

marina.schorpp@dkfz.de

1 Division of Signal Transduction and Growth Control, DKFZ-ZMBH Alliance, Im Neuenheimer Feld 280, 69120 Heidelberg, Germany

2 Faculty of Biosciences, University Heidelberg, Heidelberg, Germany

3 Department of Otorhinolaryngology, Head and Neck Surgery, Heidelberg University Hospital, Heidelberg, Germany

4 Research Group Molecular Mechanisms of Head and Neck Tumors, DKFZ, Heidelberg, Germany

5 Institute of Pathology, University of Heidelberg, Heidelberg, Germany

6 Present Address: Department of Chemistry and Biology, Ryerson University, Toronto, ON, Canada

7 Present Address: iBEST (Institute of Biomedical Engineering, Science and Technology), Toronto, ON, Canada

\section{Introduction}

Although metastasis, the spread of tumor cells from the primary tumor to a distant organ site, is highly inefficient with less than $0.02 \%$ of disseminated tumor cells being able to establish a metastatic nodule [1], it remains a major challenge in cancer therapy. Over the last years, the tumor microenvironment as a vital determinant of tumor progression and metastasis has attracted more and more attention. It is now widely accepted that tumor cells actively remodel the stromal compartment not only at the primary tumor but also at the distant organ site. This distant site remodeling takes place prior to any evidence of metastatic disease, generates a more permissive environment and, thus, facilitates metastatic outgrowth. The formation of this so-called "premetastatic niche" [2] by various tumor-derived factors and extracellular vesicles [3] involves the attraction of various immune cells, vascular remodeling and induction of angiogenesis, metabolic reprogramming and alterations in the extracellular matrix composition (reviewed in [4-6]). 
The Activating Protein-1 family member JUNB has been proven to govern multiple processes linked to pre-metastatic niche formation. Particularly in the vasculature, JUNB is of uttermost importance. In mice, global Junb deficiency results in embryonic lethality due to failure in placental and embryonic neovascularization [7]. Furthermore, JUNB is required for full induction of Vegfa upon hypoxia, tumor angiogenesis [8], and vascular contractility and motility by regulation of myosin regulatory light chain 9 [9]. In zebrafish, Junb impacts the development of the lymphatic vasculature via its direct target miR-182 [10]. Besides vascular remodeling, JUNB deficiency promotes inflammation by acting as a suppressor of multiple pro-inflammatory cytokines and chemokines, such as lipocalin-2 [11], Gmcsf [12], Cxcll [12] and Cxcl2 [12] and regulates diverse processes contributing to immunosurveillance and immune evasion in multiple immune cell types. Macrophage activation as well as CD4+ T cell polarization to $\mathrm{T}_{\mathrm{H}} 2$ cells depend on JUNB-mediated expression of $I l-1 \beta$ [13] and $I l-4$ plus Infy [14, 15], respectively. In cancer, JUNB is frequently deregulated and dependent on the cancer entity can act as tumor suppressor [16-19] or oncogene [20-22]. Multiple studies have associated JUNB with invasion and metastasis. Knockdown of Junb in tumor cells suppressed invasiveness in renal-cell carcinoma [23] and breast cancer [24], and Junb knockout reduced metastasis in an experimental metastasis model of head and neck squamous cell carcinoma [25]. In contrast, JUNB levels were negatively correlated to tumor stage and lymph node involvement in breast cancer specimens [26]. Nevertheless, these studies have not addressed the vital importance of the tumor microenvironment and neglected the complexity of the metastatic cascade.

In this study, we, thus, aimed to investigate the consequences of Junb deletion in stromal cells for metastasis, particularly for early metastatic stages. For this purpose, we applied a spontaneous breast cancer metastasis model to conditional Junb knockout mice and studied angiogenesis as well as immune cell infiltration. Here, we show that JUNB acts as a suppressor of distant metastasis, which is paralled by diminished immune cell infiltration at the initial metastatic stage.

\section{Materials and methods}

\section{Tissue microarray}

Human tissue microarray samples $(0.6 \mathrm{~mm}$ cores $)$ were obtained from the National Center for Tumor Disease (Institute of Pathology, University Hospital Heidelberg, Germany) and stained for JUNB (C37F9, CST, 1:500) by immunohistochemistry as previously described [27]. Imaging was performed on the Axio Scan.Z1 (Zeiss, Germany) and raw image files were adjusted for brightness, contrast and gamma using the Zen Blue software (Zeiss). Further details in Online Resource data and Table S1.

\section{Cells}

EO771 and EO771.LMB-mCherry cells [28] were obtained from Robin L. Anderson (Peter MacCallum Cancer Centre, Melbourne). Cells were maintained as previously described [28] and were free from Epstein-Barr virus, Squirrel-Monkey Retrovirus, mycoplasma and cross-contaminating cells from species other than mouse (Multiplexion, Heidelberg, Germany). Cells were regularly checked for mycoplasma contamination (Minerva biolabs ${ }^{\circledR}$, Berlin, Germany). EO771-GFP cells were generated by lentiviral transduction using the pLVTHM vector (Addgene, Watertown, MA, USA).

\section{Mice}

Animal care and all animal experiments were performed according to the national guidelines and approved by the local government authorities of the state Baden-Württemberg (Regierungspräsidium Karlsruhe, authorization numbers G-206/13, G-26/16, G-93/18, G-227/18).

The generation of conditional Junb knockout mice $J u n b^{\Delta / \Delta}$ had been described previously [12]. In brief, hemizygous Junb knockout mice $\left(\right.$ Jun $^{\Delta /+}$; generated by previous mating to CMV-Cre Deleter mice) were crossed with Col1 $\alpha 2-C r e$ mice, where Cre expression is driven by the Collagen type (I)-alpha2 promoter [29] starting at E8.5-9.5. Col1 $\alpha 2$-Cre-positive $J u n b^{\Delta /+}$ males were crossed to Junbflox/flox female mice [30]. As controls Junb ${ }^{+/+, \text {Coll } \alpha 2-C r e}$ mice were used. For fibroblast-specific tamoxifen-inducible Junb knockout mice, Junb ${ }^{\text {flox/flox }}$ mice were bred to Col $1 \alpha 2$-CreER (T) [31] transgenic mice, Junb ${ }^{+/+, \text {Coll } 2 \text {-CreER(T) }}$ were used as controls. Deletion of Junb was induced by Tamoxifen injection $(1 \mathrm{mg} / 100 \mu \mathrm{L}$, Sigma-Aldrich, Steinheim, Germany) i.p. on 5 consecutive days before the start of tumor experiments. All mice were on a C57BL/6N background ( $\mathrm{F}>12)$ and used for experiments at the age of 6-8 weeks.

\section{Animal experiments}

The spontaneous metastasis experiment was essentially performed as previously described [28]. For tumor induction, $1 \times 10^{5}$ EO771.LMB-mCherry cells were injected into the 4th mammary fat pad on the left. Tumor size was regularly measured using a digital caliper and volume was determined using the formula $V=1 / 2 \times$ length $\times$ width $^{2}$. For spontaneous metastasis experiments, tumors were excised at approximately $500 \mathrm{~mm}^{3}$ and mice were sacrificed 21 days after. General well-being of the mice was regularly monitored 
and mice were given analgesia with $2 \mathrm{mg} / \mathrm{kg}$ of bodyweight Meloxicam s.c. (Boehringer Ingelheim, Biberach, Germany) pre- and postoperatively. Early metastatic lungs were harvested at the time point of resection.

For the experimental metastasis assay, $5 \times 10^{5}$ EO771. LMB-mCherry or EO771-GFP were injected into the tail vein. Mice were euthanized 19 days after injection and organs were dissected for analysis. Mice injected with EO771-GFP were additionally sham-operated over the 4th mammary fat pad on the left 1 day after tail vein injection. These mice received analgesia with $2 \mathrm{mg} / \mathrm{kg}$ of bodyweight Meloxicam s.c.

Organs were collected after perfusion with PBS through the left ventricle either in $700 \mu \mathrm{L}$ QIAzol ${ }^{\circledR}$ lysis reagent (Qiagen, Hilden, Germany) and immediately snap-frozen in liquid nitrogen for subsequent DNA/RNA isolation or transferred to $4 \%$ paraformaldehyde/PBS for histological analyses. For analysis of lung metastasis, the left superior lung lobe was used for DNA/RNA isolation whereas the remaining lung was used for histology.

\section{Flow cytometric analysis}

Depending on the panel, dead cell discrimination with a fixable viability dye was performed prior to surface marker staining. After washing in PBS, a maximum of $1 \times 10^{6}$ cells was stained with freshly reconstituted fixable viability dye at $1 \mu \mathrm{L} / 1 \mathrm{~mL}$ PBS for $30 \mathrm{~min}$. Excess dye was removed by washing in PBS. Unspecific binding to Fc-receptors was blocked by resuspending in anti-CD16/CD32 antibody (clone 93, ebioscience, 1:100). After 5-10 min incubation appropriate antibody cocktails for surface marker staining (respective panels in Online Resource data) were added $2 \times$ concentrated and cells were stained for 20min on ice.

Prior to acquisition, cells were passed through a $37 \mu \mathrm{m}$ filter and viability marker 7-AAD (Becton Dickinson, Erembodegem, Belgium) was added at $3 \mu \mathrm{L} / 1 \times 10^{6}$ cells if required. Samples were analyzed either at a BD FACSCanto II or a BD LSRFortessa (BD Biosciences, San Jose, CA, USA). Cell sorting of neutrophils and macrophages was performed at a BD FACSAria1 machine (BD Biosciences) and cells were sorted into FACS buffer. Data were analyzed using FlowJo v10 (Tree Star, Inc., Ashland, OR, USA).

\section{RNA isolation}

Tissues harvested in QIAzol ${ }^{\circledR}$ lysis reagent were homogenized using an ULTRA-TURRAX® T25 (IKA® Labortechnik, Staufen, Germany) and subjected to RNA isolation using the miRNeasy® Mini Kit (Qiagen) according to manufacturer's instructions. For RNA isolation of MACS-purified neutrophils the miRNeasy® Micro Kit (Qiagen) was used.
On-column DNA digestion was performed with the RNase-Free DNase Set (Qiagen) following the manufacturer's manual.

Cell pellets obtained after centrifugation of FACSorted cells were resuspended in $100 \mu \mathrm{L}$ Extraction buffer of the Arcturus ${ }^{\circledR}$ PicoPure ${ }^{\circledR}$ RNA Isolation Kit (Thermo Fisher Scientific, Vilnius, Lithuania) and incubated for 30min at $42{ }^{\circ} \mathrm{C}$. The obtained cell extract was briefly spun down and stored at $-80{ }^{\circ} \mathrm{C}$. RNA isolation was performed following the manufacturer's instructions including on-column treatment with DNase I (Qiagen).

Quality and quantity of RNA were assessed using the NanoDrop 1000 system (PeqLab Biotechnology, Erlangen, Germany) and stored at $-80^{\circ} \mathrm{C}$ until further use.

\section{DNA isolation}

According to Ambion's ToTALLY RNA ${ }^{\mathrm{TM}}$ RNA Isolation Kit protocol (Thermo Fisher) remaining organic phases after chloroform extraction for RNA isolation were combined with an equal volume of $10 \mathrm{mM}$ Tris- $\mathrm{HCl}, 0.1 \mathrm{M}$ $\mathrm{NaCl}, 1 \mathrm{mM}$ EDTA, 1\%SDS, pH12 and mixed well. After 10 min incubation on ice, samples were centrifuged at $12000 \times g, 4{ }^{\circ} \mathrm{C}$ for $20 \mathrm{~min}$. To the aqueous phase, $1 / 15$ volume of $7.5 \mathrm{M} \mathrm{NH}_{4} \mathrm{OAc}$ and 2 volumes of $100 \%$ ethanol were added and, after inverting, the sample was stored at $-20{ }^{\circ} \mathrm{C} \mathrm{O} / \mathrm{N}$. DNA was pelleted by centrifugation at $12000 \times \mathrm{g}, 4{ }^{\circ} \mathrm{C}$ for $30 \mathrm{~min}$, washed in $70 \%$ ethanol and finally dissolved in DNase-free water. After determination of DNA quality and quantity using the NanoDrop 1000 system, DNA concentration was adjusted to $20 \mu \mathrm{g} / \mu \mathrm{L}$ and stored at $-20{ }^{\circ} \mathrm{C}$.

\section{Quantitative real-time PCR}

cDNA was generated from up to $2 \mu \mathrm{g}$ total RNA using RevertAid Reverse Transcriptase (200 U/ $\mu$ L, Thermo Fisher Scientific). Quantitative real-time PCR was performed using Power SYBR ${ }^{\mathrm{TM}}$ Green Master Mix (Applied Biosystems, Woolston, UK) on the StepOnePlus RealTime PCR system (Applied Biosystems) with cDNA corresponding to $2.5 \mathrm{ng}$ of RNA per reaction as input. Respective primers used for qPCR are listed in Table $\mathrm{S} 2$ of the Online Resource.

Metastatic load was assessed by quantification of the $m$ Cherry or Gfp reporter gene present in EO771.LMBmCherry and EO771-GFP cells, respectively, on total DNA isolated from metastatic lungs as described before [28, 32] with small adaptations: samples were analyzed with the Power SYBR ${ }^{\mathrm{TM}}$ Green assay on the StepOnePlus Real-Time PCR system (Applied Biosystems). 


\section{Immunohistochemistry/immunofluorescence}

Sections were deparaffinized, rehydrated and subsequently subjected to antigen retrieval depending on the primary antibody (Online Resource Table S3). After blocking with $10 \%$ normal goat serum (Vector Laboratories, Burlingame, CA, USA) sections were incubated with primary antibodies at $4{ }^{\circ} \mathrm{C} \mathrm{O} / \mathrm{N}$. For colorimetric signal detection, sections were treated with biotinylated secondary antibodies (1:500, Vector Laboratories) after washing with PBS followed by immersion in $3 \% \mathrm{H}_{2} \mathrm{O}_{2}$ /methanol to block endogenous peroxidases. Signal was amplified with the VECTASTAIN $®$ Elite $®$ ABC HRP Kit (Vector Laboratories) and subsequently visualized using DAB Peroxidase Substrate Kit (Vector Laboratories). Finally, sections were counterstained and mounted as described in Online Resource.

For immunofluorescent detection, sections were treated with fluorescently-labelled secondary antibodies (1:250, Thermo Fisher Scientific) and nuclei were stained with Hoechst 33342 (1:1000, chemodex, Worksop, UK). Slides were mounted using Fluorescent mounting medium (Dako, Carpintiera, CA, USA). For detection of murine JUNB, slides were immersed in $0.03 \%$ Triton-X100/PBS after deparaffinization and rehydration and heated to $60{ }^{\circ} \mathrm{C}$ for $15 \mathrm{~min}$ to allow penetration of the nuclear envelope. Slides were then allowed to cool down to RT in the same buffer, subjected to antigen retrieval and incubated with antiJUNB (C37F9, CST, Leiden, Netherlands, 1:200) at $4{ }^{\circ} \mathrm{C}$ $\mathrm{O} / \mathrm{N}$. Biotinylated secondary anti-rabbit antibody (1:500, Vector Laboratories) followed by AlexaFluor ${ }^{\circledR} 647$-labelled streptavidin (1:500, Jackson Immunoresearch, Ely, UK) was utilized for signal amplification and fluorescent detection.

Immunofluorescent co-staining of JUNB and CD31 was performed on cryo-sections. For this purpose, paraformaldehyde-fixed tissues ( $24 \mathrm{~h}$ ) were equilibrated in $30 \%$ sucrose/ PBS and embedded in Tissue-Tek®O.C.T. ${ }^{\text {TM }}$ Compound (Sakura,Torrance, CA, USA) thereafter. After air-drying the sections for 5 min and quick rinsing in PBS, staining was performed as described above.

Images were acquired on the Nikon Eclipse Ti (Nikon, Düsseldorf, Germany) or Axio Scan.Z1 (Zeiss, Oberkochen, Germany). For presentation, raw images were processed and adjusted for brightness, contrast and gamma using the Zen Blue software (Zeiss) or FIJI (Image J, National Institutes of Health, USA). Unedited images were quantified utilizing macros for FIJI (Image J) written by Damir Krunic.

Lung metastatic burden was determined by quantification of immunohistochemical staining for mCherry or GFP. Whole lung had been sectioned and images of 6-7 whole lung sections were taken using the 10x objective of the Axio Scan.Z1.

\section{Statistical analysis}

All statistical tests performed in this study are indicated in the respective figure legend, $\mathrm{p}<0.05$ was considered statistically significant. Normally distributed data were subjected to two-sided unpaired t-test, data not following a normal distribution, such as relative gene expressions and metastatic burden, were analyzed by Mann-Whitney test. Data were analyzed and visualized using GraphPad Prism 7.05 (Graphpad Software, Inc., La Jolla, CA, USA).

Further details on experimental procedures can be found in the Online Resource.

\section{Results}

\section{JUNB is highly expressed in human mammary carcinoma}

To assess JUNB levels, we stained a tissue microarray of human mammary carcinoma for JUNB by immunohistochemistry. In the majority of evaluable specimen we found JUNB to be highly expressed in tumor cells independent of clinicopathological parameters (Online Resource Fig. 1a-d and Table S1). Yet, we also noticed strong JUNB positivity in cells of the surrounding stroma, such as endothelial cells, fibroblasts and immune cells (Fig. 1a). As JUNB levels are tightly controlled and JUNB is hardly expressed in adjacent non-tumor tissue [26, 33, 34], we wondered whether this high stromal JUNB expression might impact the metastastic spread. For this purpose, we utilized a well-established conditional Junb knockout mouse (Junb ${ }^{\Delta / \Delta \text { Col1 } \alpha 2 \mathrm{Cre}}$, named JUNB KO [9, 12, 35]. Here, Junb deletion occurs not only in mesenchyme-derived but rather all stromal cells including fibroblasts, endothelial cells, pericytes and immune cells [12, 35] due to very prominent Col1 $\alpha 2$-driven Cre expression in fibroblasts [29] as well as very low level Cre expression in cells during embryonic development resulting in Junb deletion due to the permissive chromatin of this immediate early gene.

These JUNB KO mice were compared to transgenic mice being wildtype for Junb but carrying the Col1 $\alpha 2$-Cre transgene (named Junb ${ }^{+/+}$, CTR) (Fig. 1b and c). Indeed, immunofluorescent co-stainings of JUNB and cell type specific markers, revealed the absence of JUNB specifically in blood (CD31+) and lymphatic (LYVE-1+) endothelial cells as well as immune cells (CD45+) of KO but not in the CTR mice (Fig. 1c; Online Resource Fig. 1e). Furthermore, JUNB was highly expressed in EO771.LMB tumor cells (Fig. 1c; Online Resource Fig. 1e). Thus, we could use this so far only known C57BL/6-mouse-derived model of spontaneously metastatic mammary cancer [28] to analyze the contribution of stromal JUNB to metastasis. 
a
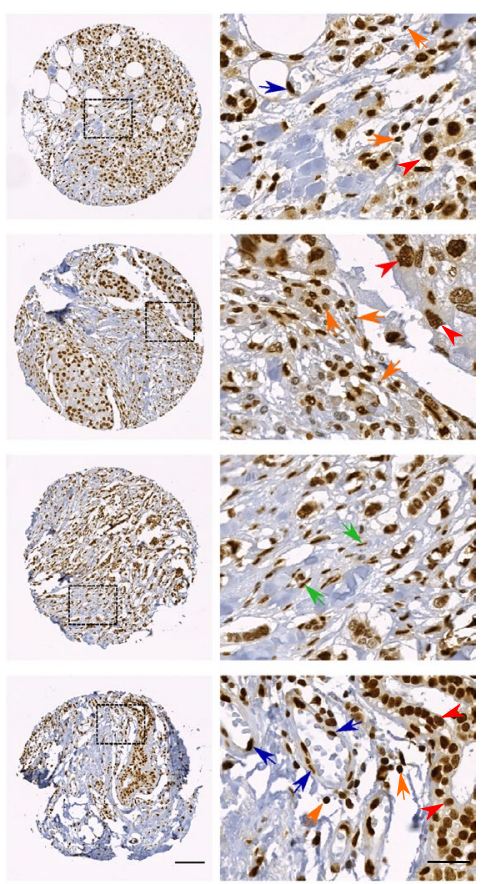

b

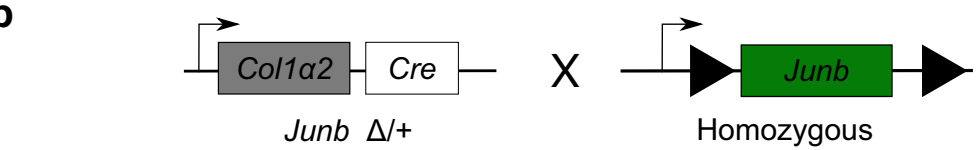

C

CTR
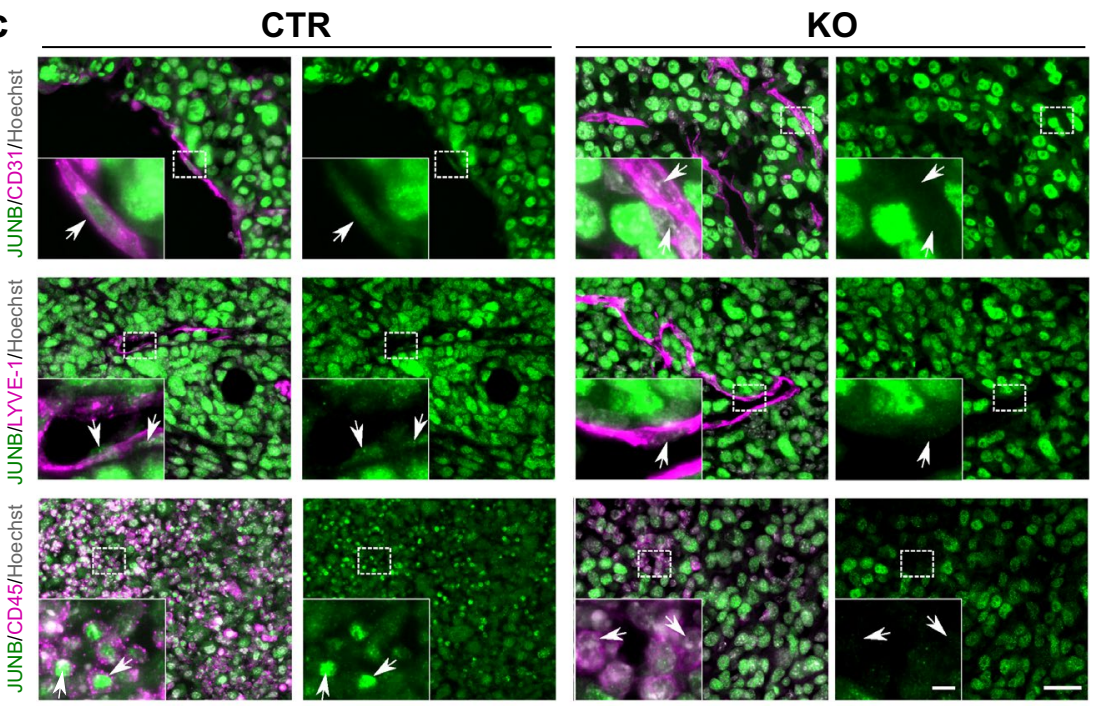

Fig. 1 JUNB expression in human and murine breast cancer tissue. a JUNB expression in tumor cells (red arrowhead), endothelial cells (blue arrow), immune cells (orange arrow) and fibroblasts (green arrow). Scale bar in overview $100 \mu \mathrm{m}$, picture on the right shows magnification of the area marked in overview, scale bar in magnification $30 \mu \mathrm{m}$. b Schematic representation of Junb knockout (KO)

\section{Stromal JUNB loss promotes distant metastasis}

In order to investigate the functional consequences of stromal JUNB loss on distant metastasis, EO771.LMB breast cancer cells tagged with a mCherry reporter [28] were orthotopically injected into the mammary fat pad of Junb KO and CTR mice and metastasis was analyzed after surgical removal of the primary tumor (Fig. 2a). In line with our previous study [35] primary tumor growth was not affected by the absence of JUNB in the tumor stroma (Fig. 2b). Yet, when macroscopically examining the lungs at the experimental endpoint, we did observe higher metastasis in $\mathrm{KO}$ mice (Fig. 2c). This impression was further confirmed by both evaluating the presence of $m$ Cherry on genomic DNA level (Fig. 2d) as well as on protein level by immunohistochemical staining (Fig. 2e and f).

\section{Loss of JUNB is associated with elevated immune cell recruitment at the early metastatic stage}

As fibroblasts represent a major component of the tumor microenvironment, we first analyzed the fibroblast content in EO771.LMB primary tumors. Fibroblast density was slightly, but significantly reduced when assessed by mice. c Immunofluorescence co-staining of EO771.LMB primary tumors of JUNB (green) with CD31 (pink, first panel, endothelial cells), LYVE-1 (pink, second panel, lymphatics) and CD45 (pink, last panel, immune cells); Hoechst (grey) marks nuclei. Scale bar $30 \mu \mathrm{m}$, in magnification $5 \mu \mathrm{m}$

immunohistochemistry for podoplanin (PDPN, Fig. 3a, Online Resource Fig. 2c) but no change was observed measuring gene expression of fibroblast activating protein (FAP, Fig. 3b). Importantly, fibroblast-specific deletion of Junb using a tamoxifen-inducible Col1 $\alpha 2-\operatorname{CreER}(\mathrm{T})$ did not affect distant metastasis excluding a cell-intrinsic fibroblastspecific effect (Fig. 3c).

In the past, our group had established JUNB as an essential regulator of neovascularization [7], angiogenesis [8] and lymphatic development [10] prompting us to investigate whether a defective vasculature may be the cause of enhanced metastatic spread. Analysis of CD31+ blood and LYVE-1+ lymphatic vascular density did not reveal any JUNB-dependent changes in EO771.LMB primary tumors (Fig. 3d and e, Online Resource Fig. 2a and b). Assessment of the blood vascular area in lungs at the initial metastatic stage by both immunofluorescence staining and gene expression analysis using the indicative vessel marker Pecam 1 revealed a slight increase upon loss of Junb (Fig. 3f and $\mathrm{g}$ ), yet, a similar tendency was also observed in naive mice (Fig. 3g). To test the integrity of the vasculature, we performed experimental metastasis assays with two different cell lines (EO771.LMB-mCherry or EO771-GFP). Intravenous injection of tumor cells did not result in enhanced 
Fig. 2 Loss of JUNB promotes distant metastasis. a Schematic representation of the spontaneous metastasis assay using EO771.LMB tumor cells. b Primary tumor growth of EO771.LMB in CTR and KO mice. Data points represent the mean, error bars SD of all mice of the respective genotype, $\mathrm{n}=15$ (CTR) and $\mathrm{n}=16(\mathrm{KO})$. c Macroscopic images of lung metastasis. d Quantification of lung metastatic burden by qPCR of the $m$ Cherry reporter compared to vimentin on DNA level. Mann Whitney test $\mathrm{p}<0.0001 . \mathrm{n}=16$ per group. $\mathrm{e}$ Representative images of the immunohistochemistry (IHC) for mCherry, scale bar $2 \mathrm{~mm}$, and the quantification thereof (f), $\mathrm{n}=12$ (CTR) and 13 (KO). Mann Whitney analysis revealed a significant increase of lung metastasis upon deletion of stromal Junb, p $=0.0257$. Data in (d) and (f) are displayed as geometric mean with geometric $\mathrm{SD}$, one data point represents one mouse, p. *p $<0.05$, $* * * * \mathrm{p}<0.0001$ a

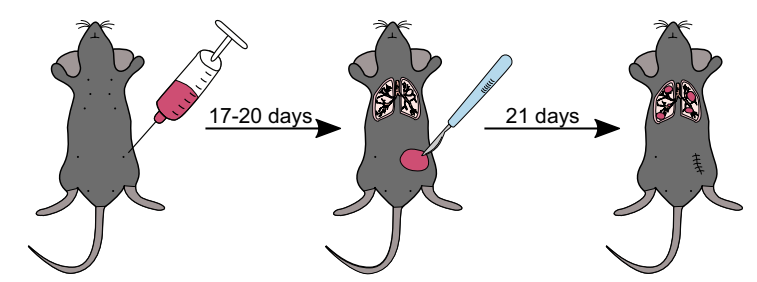

Injection of tumor cells Surgical resection at tumor size $\sim 500 \mathrm{~mm}^{3}$

c CTR
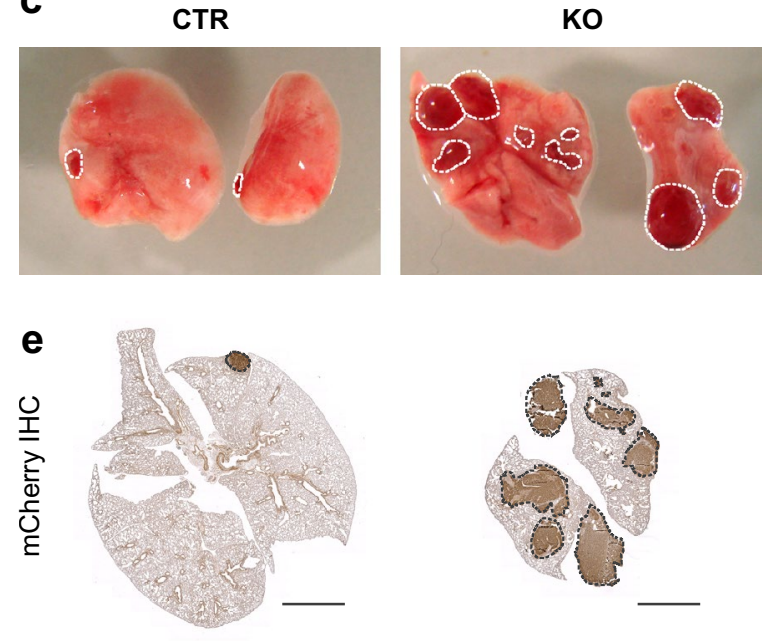

Organ dissection Analysis of lung metastasis

b Primary tumor growth
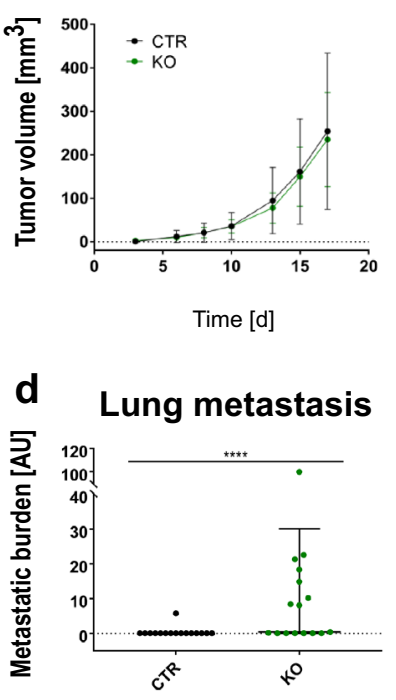

f

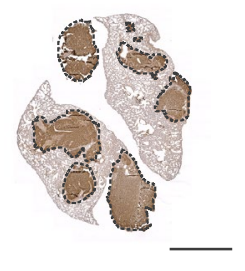

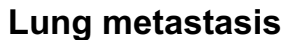

Lung metastasis

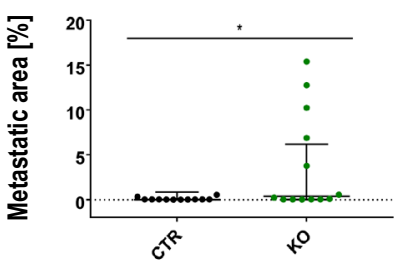

metastasis in JUNB KO mice when compared to CTR mice but rather showed an opposite tendency (Fig. 3h, Online Resource Fig. 2d-g). Hence, the vasculature of JUNB KO mice is intact.

As the immune system plays a crucial role in cancer development and progression, we next characterized the immune landscape in CTR and JUNB KO mice by flow cytometric analysis, both in the primary tumor and early metastatic lungs (gating strategy Online Resource Fig. 3a and b). JUNB-deficient mice generally displayed an enhanced immune cell infiltration compared to CTR mice, especially in the early metastatic lungs $(65.0 \pm 5.0 \%$ compared to 49.9 $\pm 7.8 \%$ CD $45+$ cells) (Fig. 4a). Further immune cell profiling revealed an elevated level of myeloid cells but fewer $\mathrm{T}$ cells in tumors and early metastatic lungs of JUNB KO mice (Fig. 4a, Online Resource Fig. 4a). Since T cell activation as measured by Interferon $\gamma$ production was not consistently impaired (Online Resource Fig. 4b and c) and also the ratio of CD4+/CD8+ T cells was not influenced by JUNB expression (Online Resource Fig. 4a), we focused on myeloid cells instead.

Monocyte $(15.1 \pm 3.3 \%$ vs. $7.8 \pm 2.9 \%)$ but even more neutrophil populations $(12.7 \pm 4.6 \%$ vs. $5.8 \pm 1.0 \%)$ were augmented in the early metastatic lungs of JUNB KO compared to CTR mice, whereas alveolar macrophages were drastically diminished $(3.1 \pm 0.8 \%$ vs. $10.4 \pm 2.4 \%)$ (Fig. 4a, Online Resource Fig. 3c, gating strategy Online Resource Fig. 3a and b). In the primary tumor, neutrophil and macrophage frequencies were not altered and the change in monocyte infiltration was not as striking as in the lung. To exclude the possibility that enhanced myeloid cell infiltration in JUNB-deficient mice is not tumor-induced but rather a result of enhanced granulopoiesis [19], we investigated the expression of immune cell markers by RT-qPCR in lungs of tumor-bearing and agematched unchallenged mice (Fig. 4b). While absence of JUNB strongly augmented the marker expression of Ptprc (CD45), Itgam (CD11b) and Ly6g in tumor-bearing mice, it hardly had any effect in unchallenged mice, in which only a much smaller rise in $L y 6 g$ expression was detected. The enhanced neutrophil infiltration especially into lungs of tumor-bearing JUNB KO mice was further confirmed by immunohistochemistry (Fig. 4c). Hence, elevated myeloid recruitment in JUNB KO mice was not caused by increased granulopoiesis but is specifically induced by the primary tumor. Taken together, JUNB-deficient myeloid cells may provide the most critical determinant for early metastasis and promote metastatic outgrowth in JUNB KO mice. 
a

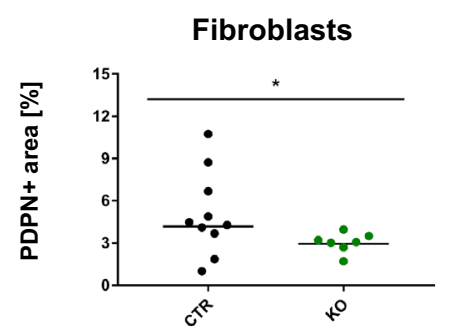

d

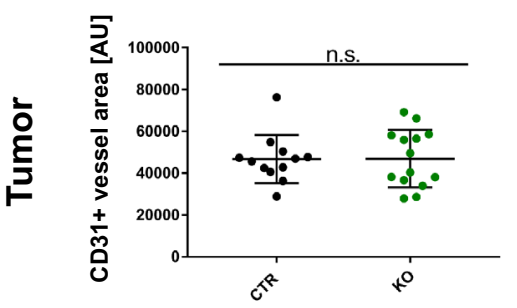

$\mathbf{f}$

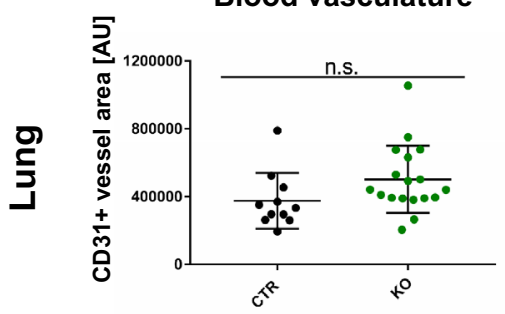

b

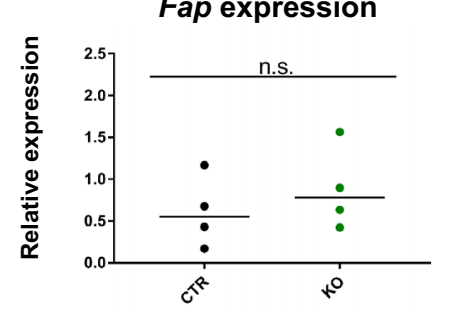

e

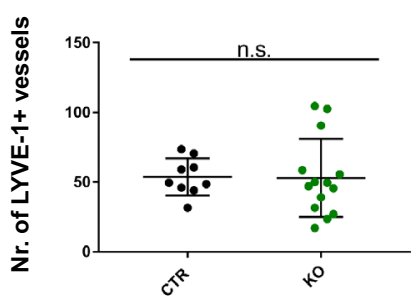

g

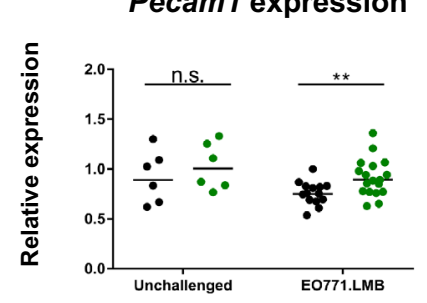

C

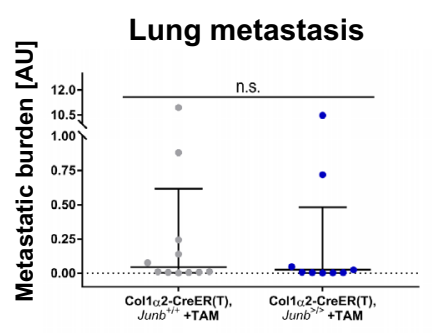

h

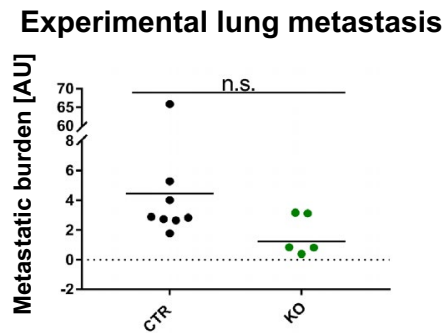

Fig. 3 JUNB does not alter fibroblast density or tumor vasculature. a, b Quantification of fibroblast content in primary tumors by immunohistochemistry for Podoplanin (a; PDPN), $\mathrm{n}=10$ (CTR) and $\mathrm{n}=7$ (KO), Mann Whitney analysis: $\mathrm{p}=0.0431$, and gene expression analysis of fibroblast activating protein (B; FAP), $\mathrm{n}=4$ for both CTR and KO, Mann Whitney: $p=0.6857$. c Distant lung metastasis in conditional fibroblast-specific mice as quantified via the presence of the $m$ Cherry reporter in tumor cells in whole genomic DNA, $\mathrm{n}=11$ $\left(\operatorname{Col} 1 \alpha 2-\operatorname{CreER}(\mathrm{T}), \mathrm{Junb}^{+/+},+\mathrm{TAM}\right)$ and $\mathrm{n}=9$ (Col1 $\alpha 2-\operatorname{CreER}(\mathrm{T})$, $J_{u n b^{>/>}}$, + TAM), data obtained from three independent injection rounds, Mann Whitney: $p=0.4119$. d Tumor blood vasculature as assessed by CD31 immunofluorescence staining. Quantification was based on two whole tumor sections with 5 random fields each. Necrotic areas were avoided. Significance was assessed by unpaired t-test, $\mathrm{p}=0.9521, \mathrm{n}=12$ (CTR) and $\mathrm{n}=14(\mathrm{KO})$. e Number of lymphatic vessels in primary tumors, LYVE-1+structures were manu-

\section{Neutrophils express high levels of tissue remodeling factors}

Neutrophils and macrophages have been described to facilitate the establishment of the pre-metastatic niche and have been assigned tumor-promoting as well as anti-tumor functions. For both subtypes, extensive studies have defined adequate markers to aid classification. To preselect relevant markers in this study, we performed gene expression profiling of circulating neutrophils in the blood isolated by MACS from tumor-bearing JUNB KO and CTR mice (Online ally counted on two whole tumor sections, $n=9$ (CTR), $n=14(\mathrm{KO})$. Unpaired t-test, $\mathrm{p}=0.9449$. f Blood vasculature in early metastatic lungs quantified by immunofluorescence staining for CD31, $\mathrm{n}=11$ (CTR), $\mathrm{n}=18(\mathrm{KO})$, unpaired t-test: $\mathrm{p}=0.0895$. $\mathrm{g}$ Gene expression analysis of Pecaml in whole lungs of unchallenged and tumor-bearing mice, $n=6$ (unchallenged CTR and KO), $n=14$ (tumor-bearing CTR), $n=18$ (tumor-bearing KO). Mann Whitney analysis of lungs from unchallenged $(\mathrm{p}=0.3939)$ and tumor-bearing mice $(\mathrm{p}=0.0079)$. h Experimental lung metastasis of EO771.LMB-mCherry cells as quantified by qPCR of the mCherry reporter on DNA level, $\mathrm{n}=8$ (CTR) and $n=5(\mathrm{KO})$ from two independent injection rounds. Significance assessed by Mann Whitney test, $\mathrm{p}=0.1709$. ${ }^{*} \mathrm{p}<0.05$, $* * \mathrm{p}<0.01$. Data are shown as means and SD in $(\mathbf{d}-\mathbf{f})$, in $(\mathbf{a}, \mathbf{b}, \mathbf{g}, \mathbf{h})$ the geometric mean and in (c) the geometric mean plus geometric SD are indicated. Data points represent individual mice

Resource Fig. 5a). Surprisingly, a classical polarization of JUNB-deficient neutrophils towards tumor-promoting functions was not detected. Instead, genes implicated in tissue remodeling and angiogenesis, such as $M m p 9$ and $B v 8$, were upregulated, whereas e.g. Arginase 1, a common marker for immunosuppression, was even expressed at lower levels in JUNB-deficient circulating neutrophils.

To investigate whether infiltrated myeloid cells may promote metastasis by vascular remodeling, we isolated neutrophils and macrophages from primary tumors and pre-metastatic lungs by Fluorescence-activated cell sorting 
a
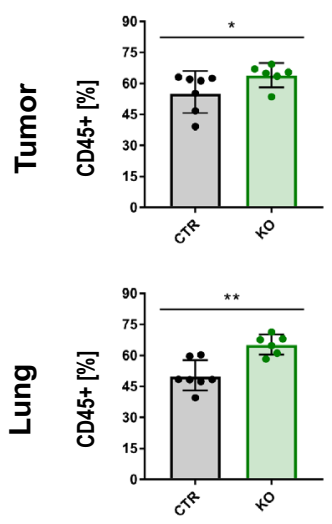

Myeloid cells
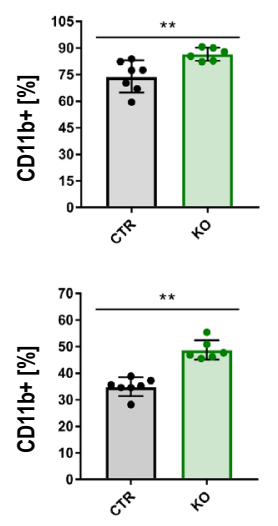

Neutrophils
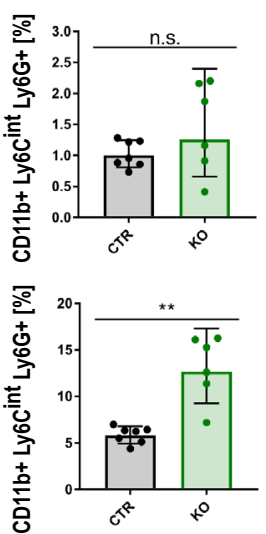

Monocytes
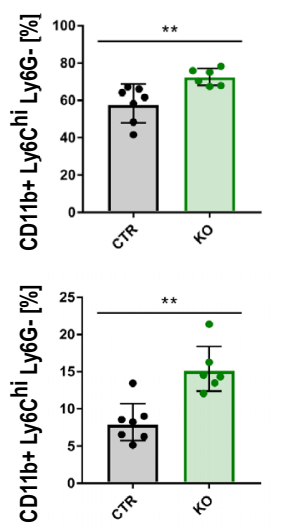

Macrophages
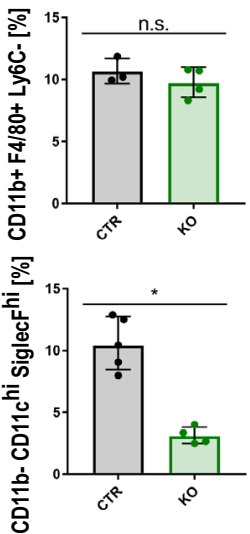

b
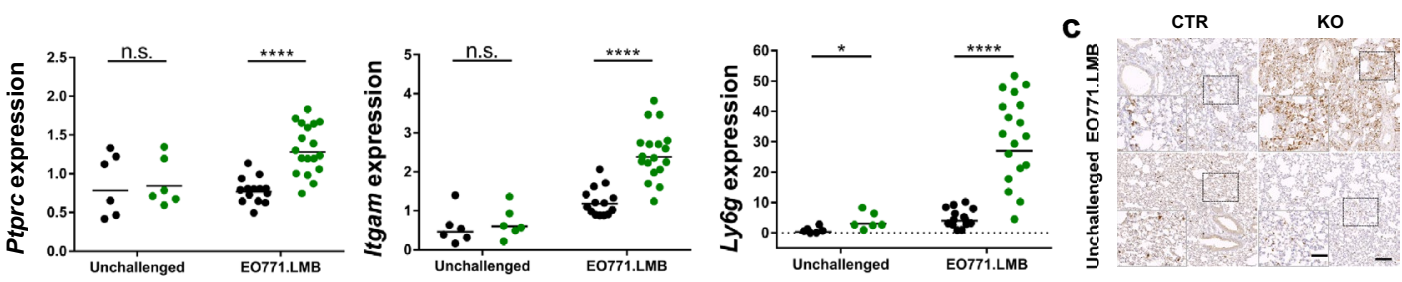

Fig. 4 Characterization of immune landscape. a Increased immune cell infiltration upon Junb loss in EO771.LMB primary tumors and early metastatic lungs as assessed by flow cytometry, $n=7$ (CTR), $\mathrm{n}=6(\mathrm{KO})$, from two independent experiments, macrophage data are obtained from one experiment with $n=3(\mathrm{CTR})$ and $n=4(\mathrm{KO})$. CD45+immune cells are displayed as fraction of all living cells; myeloid cells, neutrophils, monocytes and macrophages are related to mCherry- CD45 + living cells. b Enhanced expression of immune cell markers Ptprc (CD45), Itgam (CD11b) and Ly6g in whole lungs of unchallenged and EO771.LMB tumor-bearing mice, $n=6$ (unchal-

(FACS) and analyzed gene expression of markers identified by screening circulating neutrophils. Both $B v 8$ and Mmp 9 were expressed at a higher level in JUNB-deficient neutrophils but upregulation of Mmp9 was neither apparent in macrophages isolated from the tumor nor alveolar or interstitial macrophages from lungs at the initial metastatic stage (Fig. 5a and b, Online Resource Fig. 5b). Analyses of whole lungs confirmed the increased expression of $B v 8$ and Mmp 9 upon deletion of Junb specifically in tumor-bearing mice (Fig. 5c). Interestingly, elevated Argl expression was observed in whole lungs upon loss of JUNB (Online Resource Fig. 5d). Although no Argl upregulation was observed in isolated neutrophils or macrophages, the strong influx of neutrophils into pre-metastatic lungs may have caused overall augmented levels (Online Resource Fig. 5b). Additional markers for pro- or anti-tumor activities, such as IllO and Nos 2 were not found deregulated, neither in neutrophils nor macrophages (Online Resource Fig. 5b).

In order to functionally link increased neutrophil infiltration to enhanced metastatic load upon stromal deletion of $J u n b$, we depleted neutrophils pharmacologically using the lenged CTR and KO, n=14 (CTR EO771.LMB), $\mathrm{n}=18$ (KO EO771. LMB). c Representative images of neutrophil infiltration (neutrophil 7/4) in lungs of unchallenged and tumor-bearing mice, scale bar $100 \mu \mathrm{m}$, inset shows a magnified image of the marked area, scale bar of inset $50 \mu \mathrm{m}$. Each data point represents one mouse. Significance was determined by Mann Whitney analysis. ${ }^{*} \mathrm{p}<0.05, * * \mathrm{p}<0.01$, $* * * \mathrm{p}<0.001, * * * * \mathrm{p}<0.0001$. Heights of the bar represent geometric mean, with error bars indicating geometric SD (a), in (b) geometric mean is displayed

neutrophil depleting antibody anti-Ly6G (Online Resource Fig. 6a). Although anti-Ly6G efficiently depleted neutrophils from the blood from CTR mice, in JUNB KO mice depletion was only effective until day 10 (Online Resource Fig. 6e, gating strategy Online Resource Fig. 6f). Obviously, owing to the very high numbers of circulating neutrophils in JUNB KO mice, anti-Ly6G was not able to deplete neutrophils at later stages of tumor progression and to impair neutrophil infiltration into primary tumors and early metastatic lungs (Online Resource Fig. 6g and h). Consequently, distant metastasis was not reduced due to insufficient anti-Ly6G treatment in JUNBdeficient mice (Online Resource Fig. 6c and d). Nevertheless, this experiment confirmed the enormous increase in circulating and infiltrating neutrophils, which most likely represent the main driver for the enhanced distant metastasis upon stromal JUNB loss. 
a
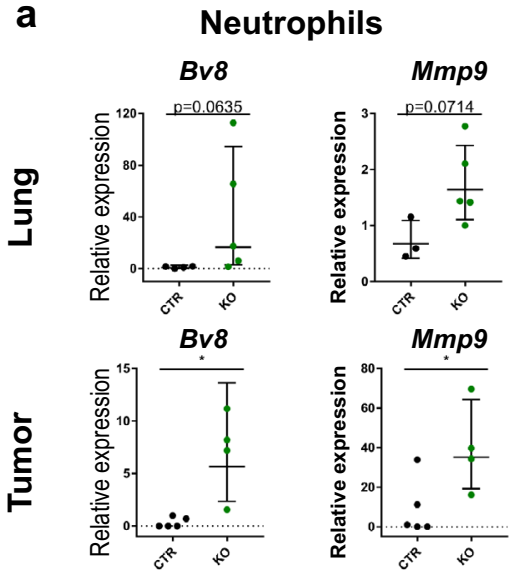

b Macrophages

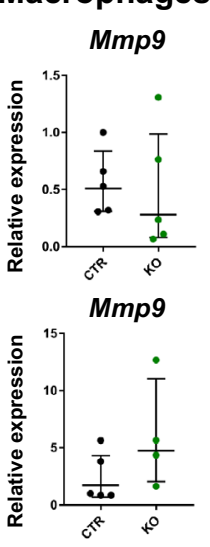

C
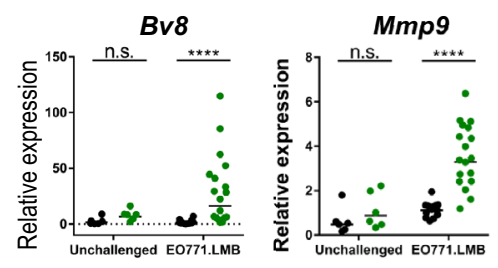

Fig. 5 Gene expression profiling of FACSorted myeloid cells from tumor-bearing JUNB KO and CTR mice. a Gene expression analysis of mCherry- CD45+CD3- B220-CD11b + Ly6G G $^{\text {hi }}$ neutrophils isolated from early metastatic lungs (upper panel) and tumors (lower panel), $n=4$ (lung CTR), $n=5$ (lung KO), $n=4$ (tumor CTR and $\mathrm{KO}$ ). $\mathbf{b}$ Expression of $M m p 9$ in alveolar macrophages in the lung (defined as CD45+CD3- B220- CD11b ${ }^{\text {low }}$ SiglecF $^{\text {hi }}$ CD11 $c^{\text {hi }}$ ) and macrophages in the primary tumor (identified as mCherry$\mathrm{CD} 45+\mathrm{CD} 3-\mathrm{B} 220-\mathrm{CD} 11 \mathrm{~b}+\mathrm{F} 4 / 80+\mathrm{Ly} 6 \mathrm{C}-$ ), $\mathrm{n}=5$ (lung CTR and $\mathrm{KO}$ ), $\mathrm{n}=5$ (tumor $\mathrm{CTR}$ ), $\mathrm{n}=4$ (tumor KO). $\mathbf{c}$ Gene expression analysis of whole lungs from tumor-bearing (EO771.LMB) and nontumor bearing unchallenged mice, $n=6$ (unchallenged CTR $+K O$ ), $\mathrm{n}=14$ (CTR EO771.LMB), $\mathrm{n}=18$ (KO EO771.LMB). Each data point represents one individual mouse. Data are presented as geometric mean \pm geometric $\mathrm{SD}(\mathbf{a}+\mathbf{b})$ or geometric mean only $(\mathbf{c})$. Statistical analysis $(\mathbf{a}-\mathbf{c})$ by Mann Whitney, ${ }^{*} \mathrm{p}<0.05$, ***p $<0.001$, $* * * * \mathrm{p}<0.0001$

\section{Discussion}

The importance of the pre-metastatic niche formation and the determinants for early metastatic seeding are well recognized. Yet, our understanding of the complex interplay between different cell types of the tumor microenvironment and the tumor cells is still insufficiently understood limiting the clinical success of therapies. The transcription factor JUNB had previously been linked to invasion and metastasis but studies had largely focused on tumor cells thereby ignoring the complexity of the tumor microenvironment $[24,25$, 36]. Here, we describe a strong JUNB expression in cells of the tumor microenvironment of human breast cancer specimens. As JUNB levels are usually tightly controlled in physiology but often deregulated in cancer, we wondered, whether stromal JUNB may drive malignancy. Indeed, by

applying a syngeneic breast cancer model of spontaneous metastasis combined with surgical excision of the primary tumor to conditional KO mice with a stromal JUNB ablation, we could identify JUNB as a strong suppressor of metastasis.

Although cancer-associated fibroblasts drive malignancy as well as invasion [37] and JUNB impacts proliferation in fibroblasts in vitro [38], we could exclude an altered fibroblast secretome as metastatic driver as fibroblast-specific deletion of JUNB did not influence distant metastasis.

Another key mediator of metastasis is a remodelled aberrant and frequently leakier vasculature promoting intravasation and extravasation of disseminated tumor cells $[2,6]$. JUNB functions as an essential regulator in the blood and lymphatic vascular system determining vessel development and homeostasis [7-10]. In line with a previous study [35], in the tumor blood and lymphatic vascular density as well as primary tumor growth were not affected by JUNB loss. However, stromal JUNB loss did result in enhanced metastasis to the lung. Therefore, we reasoned that the microenvironment in the lung may be affected differently upon Junb deletion. Indeed, lung vascular density was higher in JUNB KO mice compared to controls, irrespective of primary tumor presence. Importantly, stromal JUNB loss did not provoke an elevated metastatic burden in two independent experimental metastasis assays. Albeit the number of animals used may appear rather small, boths assays imply that the JUNB-deficient vasculature is intact and not decisive for the observed enhanced metastasis to the lung.

Immune cells are frequently recruited to the initial metastatic site and are of vital importance in cancer progression contributing to invasion and immuno-suppression. JUNB is a key transcriptional regulator of $\mathrm{T}$ cell differentiation [14, 15], macrophage activation [13] as well as a well-known inhibitor of granulocyte progenitor proliferation [19]. Characterization of the immune cell landscape in JUNB-deficient mice revealed that the metastatic phenotype in stromal JUNB KO mice does not correspond to the increased antitumor response observed in regulatory T cell-specific JUNB knockout mice [39, 40]. Moreover, as the observed effect on $\mathrm{T}$ cell infiltration was visible in the primary tumor rather than the early metastatic lungs, we reasoned that enhanced metastasis is most likely not due to altered $\mathrm{T}$ cell infiltration and focused on myeloid cells in the tumor microenvironment instead.

These cells frequently exhibit a pro-tumorigenic phenotype, fueling immunosuppression and invasion or directly enhancing metastatic seeding. Against our expectations, gene expression analysis of isolated neutrophils and macrophages in this study did not support a clear polarization towards a pro-tumorigenic phenotype upon JUNB-deficiency. Strikingly though, markers of tissue and vascular remodeling, such as the pro-angiogenic factor $B v 8$ [41] and metalloproteinase $M m p 9$ [42] were significantly upregulated 
in JUNB-deficient neutrophils. As Mmp9 is a known JUNB target [43-46] there is strong correlational evidence that Mmp9 is directly suppressed by JUNB. Our hypothesis is additionally supported by ChIP-Seq data demonstrating JUNB binding to and acting as a repressor on the $M M P 9$ promoter in oral cancer [43]. $B v 8$ could be either directly repressed by JUNB as its ortholog Bo 8 was shown to be AP-1 regulated [47] or indirectly involving a STAT3-NFkBAP-1 transcriptional network [48, 49]. Data in the ChIP atlas data base [50] show JUNB, JUN and STAT3 binding to the murine as well as human Bv8 5' region. Interestingly, both putative targets, $M m p 9$ and $B v 8$, were significantly upregulated upon stromal Junb loss both in the primary tumor and early metastatic lungs. While primary tumor growth is not affected, lung metastasis is enhanced. At first sight this may appear paradoxical as $M m p 9$ and $B v 8$ overexpression due to stromal JUNB loss should also have a positive impact on primary tumor growth. Most likely, the effect of upregulated stromal $M m p 9$ and $B v 8$ may be neglectable because the primary tumor itself is a rich source of pro-angiogenic and proinflammatory factors. By contrast, in the lungs of JUNB KO mice, the elevated influx of neutrophils in combination with the increased expression of $M m p 9$ and $B v 8$ may culminate in an overall amplification of MMP9 and Bv8, thus, facilitating metastasis. Importantly, Mmp 9 was not upregulated in JUNB KO macrophages clearly identifying infiltrating neutrophils as a major source.

To validate the hypothesis that JUNB-deficient neutrophils promote metastasis by enhancing tissue remodeling via $B \nu 8$ and $M m p 9$ production, we aimed to deplete neutrophils pharmacologically. Yet, despite the high efficiency of antiLy6G antibody in the initial phase, at later stages of tumor progression depletion was technically impossible, at least with our approach, most likely due to the vast neutrophil numbers in JUNB-deficient mice. Our findings are in line with a previous report on spontaneous metastasis from 4T1 tumors in syngeneic Balb/c mice [51] showing effective neutrophil depletion only until day 14 post tumor engraftment. Admittedly, this represents a major limitation of our study but also points out that functionally defining the decisive cell type is extremely challenging and ultimately may be impossible due to the fact that JUNB represents a multifaceted transcriptional regulator of immune cells $[13-15,19]$. As the EO771.LMB cell line is to our knowledge the only metastasizing breast cancer cell line derived from C57BL/6 mice, we were unfortunately unable to corroborate our findings in an additional breast cancer model. Thus, the functional link between augmented lung infiltration with JUNB-deficient neutrophils and enhanced metastasis remains to be formally established. However, neutrophils have frequently been attributed pro-metastatic functions [52, 53], also by inducing vascular remodeling [54]. We, therefore, consider it most likely that Junb knockout neutrophils facilitate metastasis by promoting angiogenesis and vascular remodeling in the pre-metastatic lungs. However, we cannot fully exclude a contribution of other cell types or a mechanism involving immunosuppression.

In summary, we identified JUNB as a potent suppressor of metastasis by interfering with the initial metastatic stage. As JUNB is a common downstream target of anti-proliferative cancer therapy, efforts have to be taken ensuring the design of tumor-specific therapies leaving JUNB levels in the tumor microenvironment unaffected.

Supplementary Information The online version contains supplementary material available at https://doi.org/10.1007/s10585-021-10108-9.

Acknowledgements The authors thank Prof. Robin Anderson, Peter MacCallum Cancer Centre, Melbourne, for providing the mCherrylabelled EO771.LMB cells, Dr. Damir Krunic from the DKFZ Light Microscopy Core Facility for writing macros for image analysis and Sonja Obradovic, University of Heidelberg, for automated scoring of the tissue microarray. We are grateful for the help of Dr. Tim Holland-Letz and Prof. Annette Kopp-Schneider for statistical analysis of in vivo and in vitro experiments. We also thank the DKFZ Flow Cytometry Core Facility team for cell sorting and panel design, the DKFZ Light Microscopy Core Facility for assistance in imaging, the Center for Preclinical research at the DKFZ for animal care and the National Center for Tumor Disease for providing the human tissue microarray samples.

Author contributions JW, SA-B and MS-K designed the study. JW, BK and MS-S performed all the experiments except for the TMA staining. TMA samples were provided by H-PS, staining was performed by JH. H-PS, JH and MS-K analyzed the TMA data. JW analyzed the data, made the figures and wrote the manuscript with input from the other authors. MS-K and PA conceived and funded the research.

Funding Open Access funding enabled and organized by Projekt DEAL. This work was supported by Deutsche Forschungsgemeinschaft (German Research Foundation) SFB-Transregio 23 Project B2 (to MSK) and the Helmholtz International Graduate School for Cancer Research (to JW).

Data availability Raw data are available from the corresponding author upon reasonable request.

Code availability The datasets generated and analyzed during the current study are available from the corresponding author on reasonable request.

\section{Declarations}

Conflict of interest The authors declare not to have a conflict of interest.

Ethical approval Study approval for the human tissue microarray samples obtained from the National Center for Tumor Disease was granted by the ethics committee of the University of Heidelberg (S-206/2005). Written informed consent was obtained from all patients. All experiments involving animals were performed according to the national guidelines and approved by the local government authorities of the state Baden-Württemberg (Regierungspräsidium Karlsruhe, authorization numbers G-206/13, G-26/16, G-93/18, G-227/18). 
Open Access This article is licensed under a Creative Commons Attribution 4.0 International License, which permits use, sharing, adaptation, distribution and reproduction in any medium or format, as long as you give appropriate credit to the original author(s) and the source, provide a link to the Creative Commons licence, and indicate if changes were made. The images or other third party material in this article are included in the article's Creative Commons licence, unless indicated otherwise in a credit line to the material. If material is not included in the article's Creative Commons licence and your intended use is not permitted by statutory regulation or exceeds the permitted use, you will need to obtain permission directly from the copyright holder. To view a copy of this licence, visit http://creativecommons.org/licenses/by/4.0/.

\section{References}

1. Celià-Terrassa T, Kang Y (2016) Distinctive properties of metastasis-initiating cells. Genes Dev 30(8):892-908. https://doi.org/ 10.1101/gad.277681.116

2. Kaplan RN, Riba RD, Zacharoulis S, Bramley AH, Vincent L, Costa C, MacDonald DD, Jin DK, Shido K, Kerns SA, Zhu Z, Hicklin D, Wu Y, Port JL, Altorki N, Port ER, Ruggero D, Shmelkov SV, Jensen KK, Rafii S, Lyden D (2005) VEGFR1positive haematopoietic bone marrow progenitors initiate the premetastatic niche. Nature 438(7069):820-827. https://doi.org/10. 1038/nature04186

3. Hoshino A, Costa-Silva B, Shen T-L, Rodrigues G, Hashimoto A, Tesic Mark M, Molina H, Kohsaka S, Di Giannatale A, Ceder S, Singh S, Williams C, Soplop N, Uryu K, Pharmer L, King T, Bojmar L, Davies AE, Ararso Y, Zhang T, Zhang H, Hernandez J, Weiss JM, Dumont-Cole VD, Kramer K, Wexler LH, Narendran A, Schwartz GK, Healey JH, Sandstrom P, Labori KJ, Kure EH, Grandgenett PM, Hollingsworth MA, de Sousa M, Kaur S, Jain M, Mallya K, Batra SK, Jarnagin WR, Brady MS, Fodstad O, Muller V, Pantel K, Minn AJ, Bissell MJ, Garcia BA, Kang Y, Rajasekhar VK, Ghajar CM, Matei I, Peinado H, Bromberg J, Lyden D (2015) Tumour exosome integrins determine organotropic metastasis. Nature 527(7578):329-335. https://doi.org/10. 1038/nature 15756

4. Sleeman JP (2015) The lymph node pre-metastatic niche. J Mol Med (Berl) 93(11):1173-1184. https://doi.org/10.1007/ s00109-015-1351-6

5. Peinado H, Zhang H, Matei IR, Costa-Silva B, Hoshino A, Rodrigues G, Psaila B, Kaplan RN, Bromberg JF, Kang Y, Bissell MJ, Cox TR, Giaccia AJ, Erler JT, Hiratsuka S, Ghajar CM, Lyden D (2017) Pre-metastatic niches: organ-specific homes for metastases. Nat Rev Cancer 17(5):302-317. https://doi.org/10.1038/nrc. 2017.6

6. Quail DF, Joyce JA (2013) Microenvironmental regulation of tumor progression and metastasis. Nat Med 19(11):1423-1437. https://doi.org/10.1038/nm.3394

7. Schorpp-Kistner M, Wang Z-Q, Angel P, Wagner EF (1999) JunB is essential for mammalian placentation. EMBO J 18(4):934-948. https://doi.org/10.1093/emboj/18.4.934

8. Schmidt D, Textor B, Pein OT, Licht AH, Andrecht S, SatorSchmitt M, Fusenig NE, Angel P, Schorpp-Kistner M (2007) Critical role for NF-kappaB-induced JunB in VEGF regulation and tumor angiogenesis. EMBO J 26(3):710-719. https://doi.org/ 10.1038/sj.emboj.7601539

9. Licht AH, Nübel T, Feldner A, Jurisch-Yaksi N, Marcello M, Demicheva E, Hu J-H, Hartenstein B, Augustin HG, Hecker M, Angel P, Korff T, Schorpp-Kistner M (2010) Junb regulates arterial contraction capacity, cellular contractility, and motility via its target Myl9 in mice. J Clin Invest 120(7):2307-2318. https://doi. org/10.1172/jci41749
10. Kiesow K, Bennewitz K, Gutierrez Miranda L, Stoll SJ, Hartenstein B, Angel P, Kroll J, Schorpp-Kistner M (2015) Junb controls lymphatic vascular development in zebrafish via miR-182. Sci Rep 5(1):15007. https://doi.org/10.1038/srep15007

11. Florin L, Hummerich L, Dittrich BT, Kokocinski F, Wrobel G, Gack S, Schorpp-Kistner M, Werner S, Hahn M, Lichter P, Szabowski A, Angel P (2004) Identification of novel AP-1 target genes in fibroblasts regulated during cutaneous wound healing. Oncogene 23(42):7005-7017. https://doi.org/10.1038/sj.onc. 1207938

12. Florin L, Knebel J, Zigrino P, Vonderstrass B, Mauch C, SchorppKistner M, Szabowski A, Angel P (2006) Delayed wound healing and epidermal hyperproliferation in mice lacking JunB in the skin. J Invest Dermatol 126(4):902-911. https://doi.org/10.1038/sj.jid. 5700123

13. Fontana MF, Baccarella A, Pancholi N, Pufall MA, Herbert DBR, Kim CC (2015) JUNB is a key transcriptional modulator of macrophage activation. J Immunol 194(1):177-186. https://doi.org/ 10.4049/jimmunol.1401595

14. Hartenstein B, Teurich S, Hess J, Schenkel J, Schorpp-Kistner M, Angel P (2002) Th2 cell-specific cytokine expression and allergen-induced airway inflammation depend on JunB. EMBO J 21(23):6321-6329. https://doi.org/10.1093/emboj/cdf648

15. Li B, Tournier C, Davis RJ, Flavell RA (1999) Regulation of IL-4 expression by the transcription factor JunB during $\mathrm{T}$ helper cell differentiation. EMBO J 18(2):420-432. https://doi.org/10.1093/ emboj/18.2.420

16. Schütte J, Viallet J, Nau M, Segal S, Fedorko J, Minna J (1989) jun-B inhibits and c-fos stimulates the transforming and transactivating activities of c-jun. Cell 59(6):987-997. https://doi.org/ 10.1016/0092-8674(89)90755-1

17. Thomsen MK, Bakiri L, Hasenfuss SC, Wu H, Morente M, Wagner EF (2015) Loss of JUNB/AP-1 promotes invasive prostate cancer. Cell Death Differ 22(4):574-582. https://doi.org/10.1038/ cdd.2014.213

18. Yang M-Y, Liu T-C, Chang J-G, Lin P-M, Lin S-F (2003) JunB gene expression is inactivated by methylation in chronic myeloid leukemia. Blood 101(8):3205-3211. https://doi.org/10.1182/ blood-2002-05-1598\%JBlood

19. Passegué E, Jochum W, Schorpp-Kistner M, Möhle-Steinlein U, Wagner EF (2001) Chronic myeloid leukemia with increased granulocyte progenitors in mice lacking JunB expression in the myeloid lineage. Cell 104(1):21-32. https://doi.org/10.1016/ S0092-8674(01)00188-X

20. Mathas S, Hinz M, Anagnostopoulos I, Krappmann D, Lietz A, Jundt F, Bommert K, Mechta-Grigoriou F, Stein H, Dörken B, Scheidereit C (2002) Aberrantly expressed c-Jun and JunB are a hallmark of Hodgkin lymphoma cells, stimulate proliferation and synergize with NF-kappa B. Embo J 21(15):4104-4113. https:// doi.org/10.1093/emboj/cdf389

21. Mao X, Orchard G, Lillington DM, Russell-Jones R, Young BD, Whittaker SJ (2003) Amplification and overexpression of JUNB is associated with primary cutaneous T-cell lymphomas. Blood 101(4):1513-1519. https://doi.org/10.1182/blood-2002-08-2434

22. Wang H, Birkenbach M, Hart J (2000) Expression of Jun family members in human colorectal adenocarcinoma. Carcinogenesis 21(7):1313-1317

23. Kanno T, Kamba T, Yamasaki T, Shibasaki N, Saito R, Terada $\mathrm{N}$, Toda Y, Mikami Y, Inoue T, Kanematsu A, Nishiyama H, Ogawa O, Nakamura E (2012) JunB promotes cell invasion and angiogenesis in VHL-defective renal cell carcinoma. Oncogene 31(25):3098-3110. https://doi.org/10.1038/onc.2011.475

24. Sundqvist A, Zieba A, Vasilaki E, Herrera Hidalgo C, Söderberg O, Koinuma D, Miyazono K, Heldin CH, Landegren U, ten Dijke P, van Dam H (2013) Specific interactions between Smad proteins and AP- 1 components determine TGF $\beta$-induced breast cancer cell 
invasion. Oncogene 32(31):3606-3615. https://doi.org/10.1038/ onc. 2012.370

25. Hyakusoku H, Sano D, Takahashi H, Hatano T, Isono Y, Shimada S, Ito Y, Myers JN, Oridate N (2016) JunB promotes cell invasion, migration and distant metastasis of head and neck squamous cell carcinoma. J Exp Clin Cancer Res 35(1):6. https://doi.org/10. 1186/s13046-016-0284-4

26. Kharman-Biz A, Gao H, Ghiasvand R, Zhao C, Zendehdel K, Dahlman-Wright K (2013) Expression of activator protein-1 (AP-1) family members in breast cancer. BMC Cancer 13(1):441. https://doi.org/10.1186/1471-2407-13-441

27. Schmitt K, Molfenter B, Laureano NK, Tawk B, Bieg M, Hostench XP, Weichenhan D, Ullrich ND, Shang V, Richter D, Stögbauer F, Schroeder L, de Bem PB, Visioli F, Rados PV, Jou A, Plath M, Federspil PA, Thierauf J, Döscher J, Weissinger SE, Hoffmann TK, Wagner S, Wittekindt C, Ishaque N, Eils R, Klussmann JP, Holzinger D, Plass C, Abdollahi A, Freier K, Weichert W, Zaoui K, Hess J (2019) Somatic mutations and promotor methylation of the ryanodine receptor 2 is a common event in the pathogenesis of head and neck cancer. Int J Cancer 145(12):3299-3310. https:// doi.org/10.1002/ijc.32481

28. Johnstone CN, Smith YE, Cao Y, Burrows AD, Cross RS, Ling X, Redvers RP, Doherty JP, Eckhardt BL, Natoli AL, Restall CM, Lucas E, Pearson HB, Deb S, Britt KL, Rizzitelli A, Li J, Harmey JH, Pouliot N, Anderson RL (2015) Functional and molecular characterisation of EO771.LMB tumours, a new C57BL/6-mousederived model of spontaneously metastatic mammary cancer. Dis Model Mech 8(3):237-251. https://doi.org/10.1242/dmm.017830

29. Florin L, Alter H, Gröne H-J, Szabowski A, Schütz G, Angel P (2004) Cre recombinase-mediated gene targeting of mesenchymal cells. Genesis 38(3):139-144. https://doi.org/10.1002/gene.20004

30. Kenner L, Hoebertz A, Beil FT, Keon N, Karreth F, Eferl R, Scheuch H, Szremska A, Amling M, Schorpp-Kistner M, Angel P, Wagner EF (2004) Mice lacking JunB are osteopenic due to cell-autonomous osteoblast and osteoclast defects. J Cell Biol 164(4):613-623. https://doi.org/10.1083/jcb.200308155

31. Zheng B, Zhang Z, Black CM, de Crombrugghe B, Denton CP (2002) Ligand-dependent genetic recombination in fibroblasts: a potentially powerful technique for investigating gene function in fibrosis. Am J Pathol 160(5):1609-1617. https://doi.org/10.1016/ s0002-9440(10)61108-x

32. Denoyer D, Potdevin T, Roselt P, Neels OC, Kirby L, Greguric I, Katsifis A, Dorow DS, Hicks RJ (2011) Improved detection of regional melanoma metastasis using $18 \mathrm{~F}-6$-fluoro- $\mathrm{N}-[2-$ (diethylamino)ethyl] pyridine-3-carboxamide, a melanin-specific PET Probe, by perilesional administration. J Nucl Med 52(1):115122. https://doi.org/10.2967/jnumed.110.078154

33. Mishra A, Bharti AC, Saluja D, Das BC (2010) Transactivation and expression patterns of Jun and Fos/AP-1 super-family proteins in human oral cancer. Int J Cancer 126(4):819-829. https://doi. org/10.1002/ijc. 24807

34. Bamberger AM, Methner C, Lisboa BW, Stadtler C, Schulte HM, Loning T, Milde-Langosch K (1999) Expression pattern of the AP-1 family in breast cancer: association of fosB expression with a well-differentiated, receptor-positive tumor phenotype. Int J Cancer 84(5):533-538. https://doi.org/10.1002/(sici)10970215(19991022)84:5\%3c533::aid-ijc16\%3e3.0.co;2-j

35. Braun J, Strittmatter K, Nübel T, Komljenovic D, Sator-Schmitt M, Bäuerle T, Angel P, Schorpp-Kistner M (2014) Loss of stromal JUNB does not affect tumor growth and angiogenesis. Int J Cancer 134(6):1511-1516. https://doi.org/10.1002/ijc.28477

36. Gong C, Shen J, Fang Z, Qiao L, Feng R, Lin X, Li S (2018) Abnormally expressed JunB transactivated by IL-6/STAT3 signaling promotes uveal melanoma aggressiveness via epithelialmesenchymal transition. Biosci Rep. https://doi.org/10.1042/bsr20 180532
37. Labernadie A, Kato T, Brugués A, Serra-Picamal X, Derzsi S, Arwert E, Weston A, González-Tarragó V, Elosegui-Artola A, Albertazzi L, Alcaraz J, Roca-Cusachs P, Sahai E, Trepat X (2017) A mechanically active heterotypic E-cadherin/N-cadherin adhesion enables fibroblasts to drive cancer cell invasion. Nat Cell Biol 19(3):224-237. https://doi.org/10.1038/ncb3478

38. Passegué E, Wagner EF (2000) JunB suppresses cell proliferation by transcriptional activation of p16(INK4a) expression. Embo J 19(12):2969-2979. https://doi.org/10.1093/emboj/19. 12.2969

39. Koizumi S-i, Sasaki D, Hsieh T-H, Taira N, Arakaki N, Yamasaki S, Wang K, Sarkar S, Shirahata H, Miyagi M, Ishikawa H (2018) JunB regulates homeostasis and suppressive functions of effector regulatory T cells. Nat Commun 9(1):5344. https://doi.org/10. 1038/s41467-018-07735-4

40. Wu J, Ma S, Hotz-Wagenblatt A, Angel P, Mohr K, Schlimbach T, Schmitt M, Cui G (2019) Regulatory T cells sense effector T-cell activation through synchronized JunB expression. FEBS Lett 593(10):1020-1029. https://doi.org/10.1002/1873-3468.13393

41. Shojaei F, Singh M, Thompson JD, Ferrara N (2008) Role of Bv8 in neutrophil-dependent angiogenesis in a transgenic model of cancer progression. Proc Natl Acad Sci USA 105(7):2640-2645. https://doi.org/10.1073/pnas.0712185105

42. Bekes EM, Schweighofer B, Kupriyanova TA, Zajac E, Ardi VC, Quigley JP, Deryugina EI (2011) Tumor-recruited neutrophils and neutrophil TIMP-free MMP-9 regulate coordinately the levels of tumor angiogenesis and efficiency of malignant cell intravasation. Am J Pathol 179(3):1455-1470. https://doi.org/10.1016/j.ajpath. 2011.05.031

43. Wu SY, Nin DS, Lee AY, Simanski S, Kodadek T, Chiang CM (2016) BRD4 phosphorylation regulates HPV E2-mediated viral transcription, origin replication, and cellular MMP-9 expression. Cell Rep 16(6):1733-1748. https://doi.org/10.1016/j.celrep.2016. 07.001

44. Limoge M, Safina A, Beattie A, Kapus L, Truskinovsky AM, Bakin AV (2017) Tumor-fibroblast interactions stimulate tumor vascularization by enhancing cytokine-driven production of MMP9 by tumor cells. Oncotarget 8(22):35592-35608. https:// doi.org/10.18632/oncotarget. 16022

45. Bedal KB, Grassel S, Oefner PJ, Reinders J, Reichert TE, Bauer R (2014) Collagen XVI induces expression of MMP9 via modulation of AP-1 transcription factors and facilitates invasion of oral squamous cell carcinoma. PLoS ONE 9(1):e86777. https://doi. org/10.1371/journal.pone.0086777

46. Rylski M, Amborska R, Zybura K, Michaluk P, Bielinska B, Konopacki FA, Wilczynski GM, Kaczmarek L (2009) JunB is a repressor of MMP-9 transcription in depolarized rat brain neurons. Mol Cell Neurosci 40(1):98-110. https://doi.org/10.1016/j. men.2008.09.005

47. Marsango S, di Patti MC, Barra D, Miele R (2009) The Bv8 gene from Bombina orientalis: molecular cloning, genomic organization and functional characterization of the promoter. Peptides 30(12):2182-2190. https://doi.org/10.1016/j.peptides.2009.09.007

48. Qu X, Zhuang G, Yu L, Meng G, Ferrara N (2012) Induction of Bv8 expression by granulocyte colony-stimulating factor in CD11b+Gr1+ cells: key role of Stat 3 signaling. J Biol Chem 287(23):19574-19584. https://doi.org/10.1074/jbc.M111.326801

49. Ji Z, He L, Regev A, Struhl K (2019) Inflammatory regulatory network mediated by the joint action of NF-kB, STAT3, and AP-1 factors is involved in many human cancers. Proc Natl Acad Sci USA 116(19):9453-9462. https://doi.org/10.1073/pnas.18210 68116

50. Oki S, Ohta T, Shioi G, Hatanaka H, Ogasawara O, Okuda Y, Kawaji H, Nakaki R, Sese J, Meno C (2018) ChIP-Atlas: a datamining suite powered by full integration of public ChIP-seq data. EMBO Rep. https://doi.org/10.15252/embr.201846255 
51. Granot Z, Henke E, Comen EA, King TA, Norton L, Benezra R (2011) Tumor entrained neutrophils inhibit seeding in the premetastatic lung. Cancer Cell 20(3):300-314. https://doi.org/10. 1016/j.ccr.2011.08.012

52. Coffelt SB, Kersten K, Doornebal CW, Weiden J, Vrijland K, Hau C-S, Verstegen NJM, Ciampricotti M, Hawinkels LJAC, Jonkers J, de Visser KE (2015) IL-17-producing $\gamma \delta$ T cells and neutrophils conspire to promote breast cancer metastasis. Nature 522(7556):345-348. https://doi.org/10.1038/nature14282

53. Wculek SK, Malanchi I (2015) Neutrophils support lung colonization of metastasis-initiating breast cancer cells. Nature 528(7582):413-417. https://doi.org/10.1038/nature 16140
54. Yan HH, Pickup M, Pang Y, Gorska AE, Li Z, Chytil A, Geng Y, Gray JW, Moses HL, Yang L (2010) Gr-1+CD11b+ myeloid cells tip the balance of immune protection to tumor promotion in the premetastatic lung. Cancer Res 70(15):6139-6149. https://doi. org/10.1158/0008-5472.Can-10-0706

Publisher's Note Springer Nature remains neutral with regard to jurisdictional claims in published maps and institutional affiliations. 